\title{
An Effective Reading Process: The Application of Annotation to English as a Foreign Language Reading*
}

\author{
LIU Xue-mei \\ Binzhou University, Binzhou, China
}

\begin{abstract}
In this study, the author investigated insights of 15 college students majored in English as they explored their own use of annotation strategy and how they applied this strategy in effective reading process. As an action research, the report is an attempt to explore the role played by annotation in reading comprehension in English as a Foreign Language (EFL) classrooms. By means of learner diaries, the researcher found that annotation, as an efficient writing-to-learn strategy, is able to help EFL learners to research a deeper level of engagement and to encourage active reading. The findings also suggest that reading strategy training can be integrated with reading tasks in the
\end{abstract} EFL classrooms.

Keywords: annotation, interactive reading model, learner diaries

\section{Introduction}

Interactive reading model assumes that during the reading process there is a dynamic relationship between reader and text. The process of reading comprehension is emphasized. Text itself does not encompass meanings, but is endowed with the ability to express meanings (Alderson \& Urquhart, 1984). This kind of ability can be realized only through the interaction between text and reader. Besides, an effective reader needs strong foundational knowledge about the reading process and the ways to comprehend. A view of reading as a meaning making process stems from the idea that comprehension is a transaction between the reader and the text (Kucer, 2001).

Wallace (1992) proposes that reading activities in language classrooms can be divided into three stages: pre-reading stage, while-reading stage, and post-reading stage. During the first stage, the teacher may arrange various activities, such as discussions on the content of the article to be read or predictions related to the reading material. The main purpose is to encourage active and reflective reading. By means of questions, personal idea discussions, and hypotheses testing, the schemata in learners' minds can be activated. Then they draw on their previous knowledge, especially the knowledge of the target language in order to produce a meaningful text. It is not a question of finding a single "right" answer, but of discussing, and defending if necessary, their choice of item. Besides, during this stage, it is quite necessary to eliminate the cultural misunderstandings with the help of the teachers. The while-reading activities aim to encourage learners to take full advantage of the textual context

\footnotetext{
* This paper is the initial achievements for Binzhou University Scientific research found project: The factors analysis and strategy research on college foreign language teachers' professional development. LIU Xue-mei, associate professor, master, Foreign Languages Department, Binzhou University.
} 
and their own schemata. A major problem with while-reading tasks is that the interruption of the reading flow. Wallace (1992) refutes that "this type of tasks can help readers in classroom situations to be more aware of reading process and what is involved in it, as well as their own reading strategies" (p. 100).

The third stage can never be deleted. It should not only include the traditional activity consisting of multiple-choice questions, which follow a reading passage. Besides, learners may be asked to note down the learning strategies during reading and reflect the whole learning process. Therefore, there is always a place for post-reading tasks. But as with pre- and while-reading tasks, the activities need to be motivated by the genre and content of the text, the context of learning, and particularly learners' purposes. This is why some learners develop the habit of reading without pausing to consider the ideas of the text. Annotation, as a writing-to-learn strategy for use while reading, stress the importance of pre-reading and while-reading stages for the purpose of promoting the interaction between reader and text.

The research on annotation in reading classroom was conducted among 15 sophomores at Foreign Languages Department of Binzhou University. From January 2014 to July 2014, the data were collected by means of learner diaries, which have become increasingly significant both as one of the reflective genres and as one of a battery of interpretive macro-ethnographic research techniques. In effect, diaries "have a valuable place in the overall methodological repertoire of the language researcher" (Nunan, 2003, p. 124) and "can play a central role in many aspects of professional development" (McDonough \& McDonough, 2000, p. 126). In addition, portfolios of the annotation were established for each learner in order to help the researcher to have a better understanding of their progress in their reading comprehension.

\section{Applying Annotation to Reading Comprehension}

Annotation is to highlight key ideas, note down the important information of the reading material and write one's personal ideas on the margins. Essentially, annotation is an efficient writing-to-learn strategy in reading and re-reading to improve foreign language learning (Porter-O’Donnel, 2004). As a visible record of the thoughts that emerge during reading process, it can help readers reach a deeper level of engagement and promote active reading.

To introduce annotation, the researcher selected reading passages which are short in length and interesting in content (see Appendix). The annotation types indicated in the form (as Figure 1 shows) are presented to the learners or on a piece of paper as a reference while reading. Then the researcher gave each learner a copy of the material for annotation. It is the teacher's task to help learners to distinguish between marks they might use for surface meaning and deep meaning. For example, squares, circles, and triangles are used to identify information concerning surface meaning, such as character, setting, reason, while ticking is used to mark the deep meaning. Marginal notes are especially encouraged to summarize what has been mentioned, to predict what to be next, or even to analyze the writer's writing craft. But the noting on the margins should not be long. If there are really a lot to write, the learners are asked to write in their diaries.

After the annotation, learners are asked to share what they have marked and written. They find that specific marginal comments recorded in text may vary from one learner to another and comments may change with the demands of the text, the purpose for the reading and the schemata of the learners. In addition, they can see that there are various patterns and categories that can be used as they work to make sense of their reading. During the 
annotation process, the teacher's responsibility is to add or modify if necessary. For example, the predictions made by the learners may be quite different or controversial. The teacher may write down all these predictions and encourage them to go on reading to check whether they are right or wrong. If learners are found to have neglected the noting marks where necessary, the teacher will ask for annotation based on certain type. But the main principle is not to intervene too much for the purpose of bringing the learners' creations into full play.

\begin{tabular}{l}
$\begin{array}{l}\text { Pre-reading: Examine the title or subtitle; } \\
\text { Pecide the genre (story, diary, dialogue, scientific essay, etc.); } \\
\text { Other activities to produce a meaningful text. } \\
\text { While-reading: } \\
\text { (surface meaning mark) } \\
\text { Characters } \\
\text { When } \\
\text { Where } \\
\text { Key words } \\
\text { Important information } \\
\text { (deep meaning mark) } \\
\text { Predict } \\
\text { Analyze the author's craft } \\
\text { Ask questions } \\
\text { Make connections } \\
\text { Formulate opinions } \\
\text { Reflect } \\
\text { Post-reading: } \\
\text { Re-read the reading marks and come to the conclusion. } \\
\text { Re-read the introduction part and conclusion, there may be new understanding. } \\
\text { Check the patterns and repetition to see if there is some special implications. }\end{array}$ \\
\hline
\end{tabular}

Figure 1. Marks and procedures of an notation.

Note. The learners were asked to write a diary each time when they finish reading if they are willing to do so.

Porter-O'Donnel (2004) points out that there are more than one form to annotate. For example, in a dialectical journal (Berthoff, 1987), learners can be asked to write down the quotations, phrases, and even words on the left column and annotations on the right one (see Figure 2). However, due to the time limit, this research has only adopted the form of the annotation shown in Figure 1.

\begin{tabular}{|l|l|}
\hline Textual information & Annotation \\
\hline & \\
\hline
\end{tabular}

Figure 2. Dialectal journal.

\section{Discussion and Implications}

As a reading strategy, annotation can help learners to come to know that reading is a kind of interaction. By means of diary writing, the author finds that annotation makes learners recognize the reading process. Learners have found the information which they have found before. Their motivation are highly improved. Simultaneously, some problems such as slow reading speed, bad reading habits remain unresolved.

Firstly, annotation enhances the learners' understanding of the reading process. Reading is the interaction between readers (learners) and text. During this process, what learners resort to is not only the language knowledge and schematic knowledge, but also the textual contents as the language input. Reading, therefore, is 
kind of psychological process, in which uncertain factors become less. And the process is characterized with being integrative and selective. The willingness to reflect what is going on features the most efficient readers. And reading process is one in which readers select their reading aims, determine the genre of the text as well as reading strategies (Frank, 1985). Being lack of understanding of the reading process, learners only focus on the result checking, such as the ratio of the right or wrong choices. They have never realized that reading is in nature an essential learning process. Examples of their journals are quoted to illustrate the great changes taking place in learners:

Before the training I saw reading only as a form of testing. But now I come to realize that reading is a process of learning.... By annotation, I learned how to appreciate the author's craft, express my own ideas and reflect on the deeper meaning of the text....

Simultaneously, annotation requires careful analysis by the learners of writing crafts, writing purposes. Learners are encouraged to associate what they are reading with their prior knowledge, i.e., to link the previous and coming knowledge, for the purpose of activating the cognitive schemata in learners' minds. Thus, learners are able to get deeper understanding of the reading process, instead of only superficial meanings. Their diaries show that what attracts learners' attention in the reading material now is important information and their logical ability is also improved:

While reading, I think, I can concentrate on the text and be aware of my thinking. And I know the importance to be more careful in my reading. Even now I read books at my dormitory, I still try to be an active reader.

Learners become more active in their reading. The investigation indicates when learners pay more attention to details, they usually come to know better of their learning process. Many learners have found that annotation makes them pay more attention to the understanding of meanings, instead of exercises following the text only. The following is a quotation form a learner's diary. She feels more confident reading:

I have found that I am now an active reader who focuses not only on factual information about the reading but also on the in-deep meaning of the story. I become more self-confident in my reading that for the first time I realize that I love reading.

Furthermore, learners are very active in contemplating the reading contents according to their schemata and linguistic knowledge. They then note down their opinions and ideas on the paper. These are authentic reading. The so-called authentic learning does not refer to the features of the text only. Breen (1985) extends the notion of "authenticity" to all of the elements in teaching contexts, including classroom social contexts, especially the reaction of the learners to the text. The annotation, however, can improve the authenticity of language input. As a form of reading skill to facilitate writing, annotation is helpful to learners' writings. For example, a learner writes the following in his diary:

I didn't think I was good at writing for I really couldn't find anything to write. Yet when I begin to annotate, I learn the way to write something. I use my response to discover deeper meaning and this is very helpful to keep track of the development of the story....

During the reading process, however, the fact that annotation slows down the reading speed cannot be denied. One of the main problems of annotation is that a lot of time has to be spent on reading. For example, a

\footnotetext{
${ }^{1}$ Grammatical errors in these learners' diaries have been corrected before they were quoted as the data to illustrate their learning progress in reading comprehension.
} 
learner writes the followng feeling in his diary:

It makes me read slower and I think it is not a good thing. Especially, annotating requires us to write something related to ourselves. And it is very hard for every one of us to fake something on the copy.

To this question, the researcher believes that the main aim of this investigation is to help learners to improve their understanding of the reading process and to make them totally involved in reading activity. The time spent on re-reading becomes less and less. In the light of this information, the use of annotation and reading speed is not controversial. Teachers should encourage their learners to read with different reading styles and reading speed in accordance with reading environments. The ability to adjust their reading speed according to the aims and styles of the reading material is one of the important features of efficient readers.

A further research finding is that bad reading habit is another factor to impede reading efficiency. During interviews, the researcher finds that learners with high language proficiency are more interested in reading and tend to have a more successful co-operation with teacher in the classroom. And the learners with low language proficiency indicate that, annotation is not so helpful to their reading, for they have often been puzzled by grammatical difficulties, such as new words, complex sentence structures, etc.. For this reason, they become anxious and unconsciously they return to the old reading habits, such as reading-aloud or reading word by word. In order to solve this problem, learners are asked to exchange their diaries each other to make them be more active and confident. This suggests that training of learning skills needs sufficient preparation, systematic planning, and strict administration of the design until learners are able to use these reading strategies automatically. Besides, the training of reading skills should be closely combined with the improvement of language proficiency, for reading speed depends on the automatic processing of information (WANG, 1990).

\section{Conclusion}

To sum up, the reading strategy training can be integrated with reading tasks in the classrooms. This combination can facilitate the reading comprehension to a high degree. Just as the findings indicate, by means of annotation, the interaction between learner and text can be greatly improved. The association of learners' linguistic knowledge and schematic knowledge makes learners have a deeper understanding of reading process. Furthermore, the author of this paper believes that annotation should not confine itself in the classroom, it should be used outside the classroom as well to encourage the horizon and enrich the language input.

\section{References}

Alderson, C., \& Urquhart, A. (1984). Reading in a foreign language. London: Longman.

Berthoff, A. (1987). Dialectal notebooks and the audit of meaning. In The journal book. Portsmouth: Boynton/Cook.

Breen, M. (1985). Authenticity in the language classroom. Applied Linguistics, 6(1), 61.

Frank, S. (1985). Reading. Cambridge: Cambridge University Press.

Kucer, S. B. (2001). Dimensions of literacy: A conceptual base of teachin reading and writing in school settings. Mahwah, NJ: Erlbaum.

McDonough, J., \& McDonough, S. (2000). Research methods for English language teachers. Beijing: Foreign Language Teaching and Research Press.

Nunan, D. (2003). Research methods in language learning. Shanghai: Shanghai Foreign Language Education Press.

Porter-O'Donnel, C. (2004). Beyond the yellow hightlighter: Teaching annotation skills to improve reading comprehension. English Journal, 93(5), 82-89.

Probst, R. (1988). Dialogue with a text. English Journal, 77(1), 32-38. 
Wallace, C. (1992). Reading. Oxford: Oxford of University Press.

WANG, C. M. (1990). Applied psycholinguistics-The study of psychology of foreign language learning. Changsha: Hunan Education Press.

\section{Appendix: Example of Reading Material}

There are people in Italy who can't stand soccer. Not all Canadians love hockey. A similar situation exists in America, where there are those individuals you may be one of them who yawn or even frown when somebody mentions baseball. 'Baseball to them means boring hours watching grown men in funny tight outfits standing around in a field staring away while very little of anything happens.' (1) They tell you it's a game better suited to the 19th century, slow, quiet, gentlemanly. These are the same people you may be one of them who love football because there's the sport that glorifies "the hit".

By contrast, baseball seems abstract, cool, silent, still.

On TV the game is fractured into a dozen perspectives, replays, close ups. The geometry of the game, however, is essential to understanding it. You will contemplate the game from one point as a painter does his subject; you may, of course, project yourself into the game. It is in this projection that the game affords so much space and time for involvement. The TV won't do it for you.

Take, for example, the third baseman. You sit behind the third base dugout and you watch him watching home plate. His legs are apart, knees flexed. His arms hang loose. He does a lot of this. The skeptic still cannot think of any other sports so still, so passive. 'But watch what happens every time the pitcher throws: the third baseman goes up on his toes, flexes his arms or bring the glove to a point in front of him, takes a step right or left, backward or forward, perhaps he glances across the field to check his first baseman's position.' Suppose the pitch is a ball. "Nothing happened," you say. "I could have had my eyes closed."

The skeptic and the innocent must play the game. And this involvement in the stands is no more intellectual than listening to music is. Watch the third baseman. Smooth the dirt in front of you with one foot; smooth the pocket in your glove; watch the eyes of the batter, the speed of the bat, the sound of horsehide on wood. If football is a symphony of movement and theatre, baseball is chamber music, a spacious interlocking of notes, chores and responses. 